\title{
Optimal Price Strategy under Price-Matching Policy
}

\author{
Vivian Okere, Wen Chen \\ Providence Business School, Providence College, Providence, RI, USA \\ Email: vokere@providence.edu,wchen@providence.edu
}

How to cite this paper: Okere, V. and Chen, W. (2020) Optimal Price Strategy under Price-Matching Policy. Journal of Applied Mathematics and Physics, 8, 2981-2998.

https://doi.org/10.4236/jamp.2020.812221

Received: September 17, 2020

Accepted: December 20, 2020

Published: December 23, 2020

Copyright $\odot 2020$ by author(s) and Scientific Research Publishing Inc. This work is licensed under the Creative Commons Attribution International License (CC BY 4.0).

http://creativecommons.org/licenses/by/4.0/

(c) (i) Open Access

\begin{abstract}
The paper explores the optimal price strategy under the price-matching policy. First, the paper formulates the demand function under the price match policy and then discovers the retailer's best response facing the price-matching pressure. From the theoretical analysis, we discover how the number of retailers plays an important role during the competition. When only two retailers are involved, the final prices may not converge to a single value. However, when more retailers are involved, the final price will converge to a single value. We also use numerical studies to illuminate the change of the prices over the time period, the sensitivity of the final price to the increment/decrement of initial prices. Finally, we provide managerial suggestions to both producers and retailers.
\end{abstract}

\section{Keywords}

Price-Matching Policy, Optimal Pricing, Retail Management

\section{Introduction}

The convenience of the smartphone is that it can provide instant information at any time. It dramatically changes the way people gathering information. Customers can gather instant information wherever they are. It affects customers' shopping decisions: what items they want to purchase, and which store they plan to visit.

At the same time, many articles compare those apps [1] [2] [3] [4] [5] and encourage customers to use the price-comparison app. Comparison shopping has already become a way of life. According to the Wiser survey, 96 percent of customers stated they would plan on comparing prices before making purchase decisions [6].

To capture the change of consumers' shopping behavior, retailers adjust their 
prices according to competitors' prices. According to the survey [7], retailers face pricing challenges: the increased price sensitivity of consumers and price competition from competitors.

However, in the existing research, there is no methodological paper to track the retailers' reactions facing the price-match competition under different scenarios.

In the paper, we make a literature review in Section 2, formulate the demand function and provide the optimal pricing strategy in Section 3, explore the symmetric situations in Section 4, and develop numerical studies in Section 5. In the end, we conclude the paper and list the limitation in Section 6 .

\section{Literature Review}

Today, many retailers such as Walmart, Target, Staples, etc., list their price online and promise to promise to match or beat the price of their competitors. Such refunds help price discriminate between well-informed and ill-formed consumers [8] because refunds are made only to well-informed consumers who can show that a lower price is available at another store while the ill-informed Consumers are charged higher prices. Our paper is related to two streams. One is the price-match-guarantee policy. Another is different dynamic pricing under competition.

First, price-matching guarantees (PMGs) are widely accepted in the retailer market. Several authors have argued that PMGs facilitate price tacit collusion with the result that several firms automatically match the lower price through their matching policy [9] [10] [11] [12]. These papers implicitly assume that firms automatically match a competitor's lower price suggesting that these price match guarantees are a "no hassle" task for the buyer. However, Hviid and Shaffer [13] argue that positive hassle costs borne by all buyers render PMGs much less effective because all the buyers prefer to buy from the firm with the lowest price. This undercutting continues until the market price reaches the competitive equilibrium level. Kireyev et al. [14] research focused on self-matching policy wherein the single retailer charges consumers the lower of its online and store price for the same product provided consumers show evidence of a price difference. To some extent, a self-matching pricing strategy can provide some degree of price consistency but it is different from the competitive price-matching strategies which are the primary objective of our paper. Salop [9] and Zhang [15] argued that prices increase when retailers price match each other which may imply a form of tacit collusion. Chen, Narasimhan and Zhang [12] found that competitive price matching intensifies consumers' search for the best bargain prices.

Second, the overall pricing strategy of the firm is influenced by the firm's resources, the level of competition, product evolution, and legal decisions. A pricing strategy that attains the right balance enables the firm to achieve higher profits and grow faster than its competitors. Pricing has come a long way since 
Alfred Marshall published his formal and systematic discourse in 1890 on supply and demand. Today, pricing decisions require actionable insights. The selection of the optimal price structure is an economic challenge that requires an understanding of the differences among customers within the market, the cost structure associated with the delivery of the product and the market strategy of the firm. Dynamic price competition will enlarge demand uncertainty [16] [17] [18]. For traditional small retailers, the decision about dynamic prices are not only related to their competitors but also related to their current inventory levels [19], capacity limit [20]. However, according to supply chain coordination, many big retailers such as Walmart, Target are no longer having issues on inventory and capacity. For example, Crayola is the majority crayon supplier for Target. When Target does not have enough inventory for large demand and Crayola will direct feed the demand and ship unmet demand to Target's warehouse.

Our paper discusses the design dynamic price under the price-match policy, which combines literature in the above two aspects. There are many empirical studies in the above aspects, such as Dreyer, B., Grønhaug, K. (2004) [21], Finn (2000) [22] and Hastings (2004) [23], etc. Our paper not only provides the theoretical supports for their empirical findings but also explains how retailers change over periods in numerical studies. In the end, our paper provides managerial insights for both retailers and producers.

\section{The Model, Basic Notation and Preliminaries}

$n$ retailers sell the same product to the consumer market. Demand at each retailer is determined by a demand function of the prices charged by all retailers [24] [25] [26]. Denote $p=\left(p_{1}, \cdots, p_{n}\right)$ as retailers' price profit function and $p_{-i}=\left(p_{1}, \cdots, p_{i-1}, p_{i+1}, \cdots, p_{n}\right)$ as other retailer's price functions except for the retailer $i$.

To simplify the discussion, we confine our analyses to the case where all demand functions are linear. In particular,

$$
d_{i}(\mathbf{p})=a_{i}-b_{i} p_{i}+\sum_{j \neq i} \beta_{i j} p_{j} \text { with } a_{i}>0, b_{i}>0, i=1, \cdots, n .
$$

We also assume

$$
\text { (D) } b_{i}>\sum_{j \neq i} \beta_{i j} \text { for all } i=1, \cdots, n \text {. }
$$

This is often referred to as diagonal dominance [26] [27]. The resulting inverse demand function is of the form:

$$
p_{i}=\hat{a}_{i}-\hat{b}_{i} q_{i}-\sum_{j \neq i} \hat{\beta}_{i j} q_{j}, i=1, \cdots, n \text { with } \hat{b}_{i}>0 \text { and } \hat{\beta}_{i j}>0 \text { for all } i \neq j \text {. }
$$

To attract more customers, some retailers provide the price-match guarantee. For example, Target says "competitor catalogs can be matched as long as the catalog displays a current data, retailer price and meet all other competitor ad match qualifications". For the purpose of comparing prices, a few shopping apps exist such as BuyVia, RedLaster, Amazon Price Check, Decide and ShopSavvy 
etc. After making a purchase, some consumers would verify that the price they paid is fair by comparing the price of the same purchase with another retailer. If other retailers offer a cheaper price, consumers may ask for price match (i.e. the difference between the purchase price and the cheaper price from other retailers).

We assume the percentage of customers of the retailer i's asking for price match is $\gamma_{i}$.

Denote $g_{\min }\left(x_{1}, \cdots, x_{m}\right):=\min \left\{x_{1}, \cdots, x_{m}\right\}$ and $g_{\max }\left(x_{1}, \cdots, x_{m}\right):=\max \left\{x_{1}, \cdots, x_{m}\right\}$. Further, let $v^{(m)}$ be an index satisfying that $p_{v^{(m)}}^{(m)}=g_{\min }\left(\mathbf{p}^{m}\right)$ and $u^{(m)}$ be an index satisfying that $p_{u^{(m)}}^{(m)}=g_{\max }\left(\mathbf{p}^{m}\right)$. Denote $v=v^{(0)}$ and $u=u^{(0)}$.

Assume that the supplier charges retailer $i$ a constant per-unit wholesale price $w_{i}$. The retailer $i$ s profit function is given by

$$
\begin{aligned}
\pi_{i}\left(p_{i}, \mathbf{p}_{-i}\right) & =\left[\left(1-\gamma_{i}\right) p_{i}+\gamma_{i} g_{\min }(\mathbf{p})-w_{i}\right] d_{i}(\mathbf{p}) \\
& =\left[\left(1-\gamma_{i}\right) p_{i}+\gamma_{i} g_{\min }(\mathbf{p})-w_{i}\right]\left[a_{i}-b_{i} p_{i}+\sum_{j \neq i} \beta_{i j} p_{j}\right]
\end{aligned}
$$

(2) implies two scenarios. If $g_{\min }(\mathbf{p})=p_{i}$, then all customers will be charged $p_{i}$. Alternative, if $g_{\min }(\mathbf{p})<p_{i}$, the percentage of customers asking for the price-match will be $\gamma_{i}$.

Assume each price closed interval is wide enough to include any equilibrium value of $p_{i}$ as an interior point.

Using $f_{i}\left(\mathbf{p}_{-i}\right)$ to denote retailer $i$ s best response to other retailer's price profile $\mathbf{p}_{-i}$. Let $f(\mathbf{p})=\left(f_{1}\left(\mathbf{p}_{-1}\right), f_{2}\left(\mathbf{p}_{-2}\right), \cdots, f_{n}\left(\mathbf{p}_{-n}\right)\right)$ be all retailers' best response vector to all retailers' prices. To simplify the further discussion, denote $\mathbf{p}^{(m)}=\mathbf{f}^{m}(\mathbf{p})$ and $\mathbf{p}^{(m)}=\left(p_{1}^{(m)}, \cdots, p_{n}^{(m)}\right)$.

An equilibrium $\mathbf{p}^{*}$ is a fixed point of $\mathbf{f}($.$) : one that satisfies \mathbf{p}^{*}=\mathbf{f}\left(\mathbf{p}^{*}\right)$. An equilibrium with is upside stable (downside stable) when there exists $\delta>0$, such that for any $\mathbf{p}$ with some $i$ satisfying $0<p_{i}-p_{i}^{*}<\delta \quad\left(0>p_{i}-p_{i}^{*}>-\delta\right)$ and $\mathbf{p}_{-i}=\mathbf{p}_{-i}^{*}$,

$$
\lim _{m \rightarrow+\infty} \mathbf{f}^{m}(\mathbf{p})=\lim _{m \rightarrow+\infty} \mathbf{f}^{m}\left(\mathbf{p}^{*}\right)=\mathbf{p}^{*}
$$

where $\mathbf{f}^{m}(\mathbf{p})$ is defined iteratively through $\mathbf{f}^{0}(\mathbf{p})=\mathbf{p}$ and $\mathbf{f}^{m}(\mathbf{p})=\mathbf{f}\left(\mathbf{f}^{m-1}(\mathbf{p})\right)$. Therefore, $\mathbf{p}^{*}$ is not weakly stable if for any $\delta>0$, there exists $\mathbf{p}$ and $i$ with $\left|p_{i}-p_{i}^{*}\right|<\delta$ and $\mathbf{p}_{-i}=\mathbf{p}_{-i}^{*}$ so that $\mathbf{f}^{m}(\mathbf{p})$ does not converge to $\mathbf{p}^{*}$. An equilibrium is stable when it is both upside stable and downside stable.

Lemma 1. The best response of retailer $i$ can be expressed by one of the following expressions.

- $f_{i}\left(\mathbf{p}_{-i}\right)=\min \left\{\frac{a_{i}-b_{i} w_{i}+\sum_{l \neq i} \beta_{i l} p_{l}}{2 b_{i}}, g_{\text {min }}\left(\mathbf{p}_{-i}\right)\right\}$ or

- $f_{i}\left(\mathbf{p}_{-i}\right)=\max \left\{\frac{a_{i}-b_{i} w_{i}+\sum_{l \neq i} \beta_{i l} p_{l}}{2 b_{i}}-\frac{\gamma_{i}}{2\left(1-\gamma_{i}\right)}\left(g_{\text {min }}\left(\mathbf{p}_{-i}\right)+w_{i}\right), g_{\min }\left(\mathbf{p}_{-i}\right)\right\}$.

The best price response depends on the internal mechanism of the market; specifically, if the maximum price is lower than all outside prices, the retailer will 
adopt the optimal price. We also infer that if the price is still lower than all outside prices after subtracting the effect of price match policy from the maximum price, the retailer will adopt the lowest price.

The best price response given the three probable scenarios depends on the "internal mechanism" of the market; specifically, if the maximum price is lower than all outside prices, the retailer will adopt the optimal price. We also infer that if the price is still lower than all outside prices after subtracting the effect of price match policy from the maximum price, the retailer will adopt the lowest price.

From Lemma 1, we have

$$
\begin{aligned}
& \frac{a_{i}-b_{i} w_{i}+\sum_{l \neq i} \beta_{i l} p_{l}}{2 b_{i}}-\frac{\gamma_{i}}{2\left(1-\gamma_{i}\right)}\left(g_{\text {min }}\left(\mathbf{p}_{-i}\right)+w_{i}\right) \\
& \leq f_{i}\left(\mathbf{p}_{-i}\right) \leq \frac{a_{i}-b_{i} w_{i}+\sum_{l \neq i} \beta_{i l} p_{l}}{2 b_{i}}
\end{aligned}
$$

Specifically, we have if $\gamma_{i}=0$,

$$
f_{i}\left(\mathbf{p}_{-i}\right)=\frac{a_{i}-b_{i} w_{i}+\sum_{l \neq i} \beta_{i l} p_{l}}{2 b_{i}} .
$$

Bernstein [25] [27] prove that the existences of the unique equilibrium if without price match guarantee, i.e. $\gamma_{i}=0$ for all $i$. In the following discussion, we will find that the uniqueness may be violated. Therefore, the convergence their paper proposed will not hold when competing retailers provide price match guarantee.

\section{Symmetric Retailers}

In this section, we consider the symmetric case with $n$ competing retailers. Specifically, let $a_{i}=a, b_{i}=b, w_{i}=w$ and $\beta_{i j}=\beta, \gamma_{i}=\gamma$ for all $i, j$. We first assume that retailers all adopt price match guarantee and the percentage of retailers using price match guarantee is the same also. Denote

$$
n_{\min }(\mathbf{p})=\sum_{i=1}^{n} 1_{p_{i}=g_{\min }(\mathbf{p})}
$$

where $1_{x}=1$ if $x$ is true and $1_{x}=0$ if $x$ is false. $n_{\min }(\mathbf{p})$ represents the number of retailers charging the lowest price.

Under symmetric case, all retailers with price match guarantee. To simplify the following discussion, denote the highest and lowest equilibrium prices respectively as where:

$$
\lambda^{\frac{N E}{E}}(n)=\frac{a-\frac{b w}{1-\gamma}}{\frac{2-\gamma}{1-\gamma} b-\beta(n-1)}, \lambda^{\overline{N E}}(n)=\frac{a-b w}{2 b-\beta(n-1)} .
$$

It can be verified that $\lambda^{\frac{N E}{N}}(n)=\lambda^{\overline{N E}}(n)=\frac{a-b w}{2 b-\beta(n-1)}$, if $\gamma=0$ and $\lambda^{\underline{N E}}(n)<\lambda^{\overline{N E}}(n)=\frac{a-b w}{2 b-\beta(n-1)}$, if $\gamma \in(0,1]$. In the following discussion, we 
will show that equilibrium exists in a range $\left[\frac{a-\frac{b w}{1-\gamma}}{\frac{2-\gamma}{1-\gamma} b-\beta(n-1)}, \frac{a-b w}{2 b-\beta(n-1)}\right]$.

However, none of them is stable. Notice that $\lambda=(>,<) \lambda^{\frac{N E}{E}}(n)$ is the unique solution for

$$
\frac{a-b w+\beta(n-1) \lambda}{2 b}-\frac{\gamma}{2(1-\gamma)}(\lambda+w)=(<,>) \lambda .
$$

and $\lambda=(>,<) \lambda^{\overline{N E}}(n)$ is the unique solution for

$$
\frac{a-b w+\beta(n-1) \lambda}{2 b}=(<,>) \lambda \text {. }
$$

In the following discussion, we find that an equilibrium price exists in the range of $\left[\lambda^{\frac{N E}{E}}, \lambda^{\frac{N}{N E}}\right]$. In the symmetric case, there is price convergence as all retailers attain equilibrium price. Additional details can be found in Lemma 2.

Lemma 2. $\mathbf{p}^{*}$ is an equilibrium if and only if $p_{i}^{*}=p_{j}^{*}$ and $p_{i}^{*} \in\left[\lambda^{\frac{N E}{N}}(n), \lambda^{\overline{N E}}(n)\right]$ for all $i, j$.

A special case without the price-match policy exists, i.e. $\gamma=0$, i.e. and $\lambda^{\frac{N E}{2}}(n)=\lambda^{\overline{N E}}(n)$. That is to say, if without price match policy, there exists an unique equilibrium, $p_{i}^{*}=\lambda^{\underline{N E}}(n)=\lambda^{\overline{N E}}(n)$. It is consistent with Bernstein [25] [27]. Their paper also shows that iterating from an arbitrary price portfolio will converge to the unique equilibrium. However, there is infinite equilibrium when $\gamma>0$. The convergence in the general case can be verified in the following Theorem.

\section{Theorem 1.}

For any $\mathbf{p}$,

$$
\lim _{m \rightarrow+\infty} g_{\max }\left(\mathbf{f}^{m}(\mathbf{p})\right) \leq \lambda^{\overline{N E}}(n) \text { and } \lim _{m \rightarrow+\infty} g_{\min }\left(\mathbf{f}^{m}(\mathbf{p})\right) \geq \lambda^{N E}(n) .
$$

Further, if $n \geq 3$, then there exists $p_{e} \in\left[\lambda^{\underline{N E}}(n), \lambda^{\overline{N E}}(n)\right]$ such that $\lim _{m \rightarrow+\infty} \mathbf{f}^{m}(\mathbf{p})=\left(p_{e}, \cdots, p_{e}\right)$.

Theorem 1 indicates best response will drive retailers' prices to a certain interval after a few iterations. When $\gamma=0$, the interval turns to be a point. That is to say, whenever the start point is, the best response vector will converge to $\lambda^{\overline{N E}}(n)$ when $\gamma=0$. It is consistent with the result and algorithm of Bernstein [25] [27]. Difference with Bernstein [25] [27], the iteration cannot converge to a unique point in the general case $\gamma>0$. In the general case, i.e., $\gamma>0$ and $n \geq 3$, all retailers eventually will charge the same price and the range of the uniform price can be given. Further, we will discuss how retailers change their prices during iterations. First, we will discuss a special case with two retailers.

In the next Theorems, we will emphasize the best response for retailers in different range.

Theorem 2.

\section{follows.}

Given different $\frac{\sum_{j \neq i} p_{j}}{n-1}$ and $g_{\min }\left(\mathbf{p}_{-i}\right)$, the best response for Retailer $i$ is as 


\begin{tabular}{|c|c|c|}
\hline$\frac{\sum_{j \neq i} p_{j}}{n-1}$ & $g_{\min }\left(\mathbf{p}_{-i}\right)$ & $f_{i}\left(\mathbf{p}_{-i}\right)$ \\
\hline$\geq \lambda^{\overline{N E}}$ & $\geq \lambda^{\overline{N E}}$ & $\lambda^{\overline{N E}} \leq f_{i}\left(\mathbf{p}_{-i}\right) \leq g_{\min }\left(\mathbf{p}_{-i}\right)$ \\
\hline$\geq \lambda^{\overline{N E}}$ & {$\left[\lambda^{\underline{N E}}, \lambda^{\overline{N E}}\right]$} & $\lambda^{N E} \leq g_{\min }\left(\mathbf{p}_{-i}\right) \leq f_{i}\left(\mathbf{p}_{-i}\right) \leq \frac{\sum_{j \neq i} p_{j}}{n-1}$ \\
\hline$\geq \lambda^{\overline{E E}}$ & $\leq \lambda^{\underline{N E}}$ & $g_{\min }\left(\mathbf{p}_{-i}\right) \leq \lambda^{\underline{N E}} \leq f_{i}\left(\mathbf{p}_{-i}\right) \leq \frac{\sum_{j \neq i} p_{j}}{n-1}$ \\
\hline$\left[\lambda^{\underline{N E}}, \lambda^{\overline{N E}}\right]$ & {$\left[\lambda^{\underline{N E}}, \lambda^{\overline{N E}}\right]$} & $\lambda^{\underline{N E}} \leq g_{\min }\left(\mathbf{p}_{-i}\right) \leq f_{i}\left(\mathbf{p}_{-i}\right) \leq \lambda^{\overline{N E}}$ \\
\hline$\left[\lambda^{N E}, \lambda^{\overline{N E}}\right]$ & $\leq \lambda^{N E}$ & $g_{\min }\left(\mathbf{p}_{-i}\right) \leq \lambda^{\underline{N E}} \leq f_{i}\left(\mathbf{p}_{-i}\right) \leq \lambda^{\overline{N E}}$ \\
\hline$\leq \lambda^{N E}$ & $\leq \lambda^{N E}$ & $\frac{\sum_{j \neq i} p_{j}}{n-1} \leq f_{i}\left(\mathbf{p}_{-i}\right) \leq \lambda^{\overline{N E}}$ \\
\hline
\end{tabular}

\section{Theorem 3.}

The following statements are true for $n=2$.

1) If $p_{1} \geq p_{2}$, then $p_{1}^{(2 m)} \geq p_{2}^{(2 m)}$ and $p_{1}^{(2 m+1)} \leq p_{2}^{(2 m+1)}$, for every $m \in N$.

2) Price pattern is as follows.

\begin{tabular}{cc}
$\left(p_{1}, p_{2}\right)$ & Price Pattern for $n=2$ \\
\hline$p_{1} \geq p_{2} \geq \lambda^{\overline{N E}}(n)$ & $\lim _{k \rightarrow+\infty} p_{1}^{(k)}=\lim _{k \rightarrow+\infty} p_{2}^{(k)}=\lambda^{\overline{N E}}(n)$ \\
$p_{1} \geq \lambda^{\overline{N E}}(n) \geq p_{2} \geq \lambda^{\underline{N E}}(n)$ & $\lim _{k \rightarrow+\infty}\left(p_{1}^{(2 k)}, p_{2}^{(2 k)}\right)=\left(\lambda^{\overline{N E}}(n), p_{2}\right)$, \\
$p_{1} \geq \lambda^{\overline{N E}}(n) \geq \lambda^{\frac{N E}{2}}(n) \geq p_{2}$ & $\lim _{k \rightarrow+\infty}\left(p_{1}^{(2 k+1)}, p_{2}^{(2 k+1)}\right)=\left(p_{2}, \lambda^{\overline{N E}}(n)\right)$ \\
$\lambda^{\overline{N E}}(n) \geq p_{1} \geq p_{2} \geq \lambda^{\underline{N E}}(n)$ & $\left(p_{1}^{(2 k)}, p_{2}^{(2 k)}\right)=\left(p_{1}, p_{2}\right)$, \\
& $\lim _{k \rightarrow+\infty}\left(p_{1}^{(2 k)}, p_{2}^{(2 k)}\right)=\left(\lambda^{\overline{N E}}(n), \lambda^{\underline{N E}}(n)\right)$, \\
$\lim _{k \rightarrow+\infty}\left(p_{1}^{(2 k+1)}, p_{2}^{(2 k+1)}\right)=\left(\lambda^{\underline{N E}}(n), \lambda^{\overline{N E}}(n)\right)$ \\
$\left.\lambda^{\overline{N E}}(n) \geq p_{1} \geq \lambda^{(2 k+1)}, p_{2}^{(2 k+1)}\right)=\left(p_{2}, p_{1}\right), k \in N$. \\
$\lim _{k \rightarrow+\infty}\left(p_{1}^{(2 k)}, p_{2}^{(2 k)}\right)=\left(p_{1}, \lambda^{\underline{N E}}(n)\right)$, \\
$\lim _{k \rightarrow+\infty}\left(p_{1}^{(2 k+1)}, p_{2}^{(2 k+1)}\right)=\left(\lambda^{\underline{N E}}(n), p_{1}\right)$ \\
$\lim _{k \rightarrow+\infty} p_{1}^{(k)}=p_{2}^{(k)}=\lambda^{N^{N E}}(n)$
\end{tabular}

A trivial case in Theorem 3 is that both retailers charge the same price then equilibrium can be obtained. If two retailers charge different prices, then the convergence will be broken. It can be explained as follows. Intuitively, if the retailer observes his opponent provide higher price, he would prefer to switch to high price. If the retailer observes his opponent provide lower price, he will afraid his profit be affected by the price match policy and then he prefers directly dropping down his price to avoid the price match. The phenomena will disappear, when there are three retailers. Notice that Theorem 1 shows that all retail- 
ers will charge the same price when the number of retailers equals to or is bigger than three.

Theorem 4.

If $n \geq 3$, then the following statement is true.

1) If $p_{i} \in\left[\lambda^{\underline{N E}}(n), \lambda^{\overline{N E}}(n)\right]$ for all $i$, then

$$
\left[g_{\text {min }}(f(\mathbf{p})), g_{\text {max }}(f(\mathbf{p}))\right] \subseteq\left[g_{\text {min }}(\mathbf{p}), g_{\text {max }}(\mathbf{p})\right] .
$$

2) If $p_{i} \in\left(\lambda^{\underline{N E}}(n), \lambda^{\overline{N E}}(n)\right]$ for all $i$ and $g_{\max }(\mathbf{p})<2 g_{\min }(\mathbf{p})-\lambda^{\underline{N E}}(n)$, then

$$
\mathbf{f}^{m}(\mathbf{p})=\left(g_{\text {min }}(\mathbf{p}), \cdots, g_{\text {min }}(\mathbf{p})\right), \forall m \geq 2 .
$$

3) If $g_{\text {min }}(\mathbf{p})=\lambda^{\frac{N E}{2}}(n)$ and $g_{\max }(\mathbf{p}) \in\left(\lambda^{\frac{N E}{2}}(n), \lambda^{\overline{N E}}(n)\right]$, then

$$
g_{\min }\left(\mathbf{f}^{m}(\mathbf{p})\right)>\lambda^{\underline{N E}}(n), \forall m \geq 2 .
$$

Theorem 4(1) tells the best response of retailers will reduce retailers' price differences in each iteration. The second results show that retailers would prefer to charge the lowest price if the difference of prices is not high. The third result investigates the one retailer charges the lower bound of the equilibrium and at least one retailer charge higher price. It shows that eventually all retailer prefers to charge a price which is higher than the lower bound.

The interesting question is that what will happen if one retailer drops the price or increases the price a little bit.

\section{Theorem 5.}

Assume $\mathbf{p}=(p, \cdots, p), \quad p \in\left[\lambda^{N E}(n), \lambda^{\overline{N E}}(n)\right], \quad \gamma>0$ and $n \geq 3$. Then the following statements are true.

1) When $p \in\left(\lambda^{\frac{N E}{2}}(n), \lambda^{\overline{N E}}(n)\right], \mathbf{p}$ is upside stable and is not downside stable.

2) When $p=\lambda^{\underline{N E}}(n)$, then $\mathbf{p}$ is not upside stable. Further, if $\frac{\gamma}{1-\gamma} \leq \frac{\beta}{b}$, $\mathbf{p}$ is downside stable. However, if $\frac{\gamma}{1-\gamma}>\frac{\beta}{b}, \mathbf{p}$ is not downside stable.

Theorem 5 tells generally when retailers reach an equilibrium, all retailer will drop their prices if one retailer charges a lower price. If one retailer increases his price, the higher price will not sustain for a long time. However, if all retailers reach the equilibrium with the lowest price, then a retailer charging a higher price will drive other retailers to charge a higher price. We also find that if a retailer charges to a lower price and price match rate is low, then eventually he will increase his price to the lowest equilibrium. However, if price match rate is high and a retailer changes to a lower price, then instead of drawing prices of other retailers down, it eventually leads to an equilibrium with a higher price.

\section{Numerical Study}

\subsection{Two Symmetric Retailers}

The base parameters for two symmetric retailers are as follows: $a_{i}=30$, 
$b_{i}=2.5, \quad \beta_{i j}=0.7, \omega_{i}=4, \quad \gamma_{i}=20 \%, \forall i, j=1,2 ; i \neq j$.

From above parameters, we will have Feasible-Price interval $\left[\lambda^{\frac{N E}{N}}(n), \lambda^{\overline{N E}}(n)\right]=[3.55,4.65]$.

Example 1. Initial prices for Retailers 1 and 2 are as follows: $p_{1}=4.3$ and $p_{2}=4.6$.

The result is discovered in Figure 1. Two dotted horizontal lines represent bounds of Feasible-Price interval. Example 1 shows that when the initial prices of two Retailers are within the Feasible-Price interval, the two Retailers will keep on switch their prices. We observe that in period 1, Retailer 2's price of 4.6 is relatively higher than Retailer 1's price and to avoid losing its customers. Retailer 2 reduces its price to match the lower price of Retailer 1 of 4.3 in the next period.

On the other hand, Retailer 1 starts off at a lower price of 4.3 in period 1 but realizes that she can charge a higher price and subsequently will increase its price to 4.6 in the next period.

Over periods, the statuses of Retailers' prices are switched with Retailer 2's price lower than Retailer 1's price. We also observe that the Retailer with a higher price facing the potential of losing its customers would charge a lower price in the next period to increase its market share. Conversely, the Retailer with a lower price seizes the opportunity of charging a higher price and increases its prices in the next period. With competition between the two Retailers, they will switch prices in each period.

Example 2. Initial prices for Retailers 1 and 2 are as follows: $p_{1}=4.5$ and $p_{2}=6.5$.

The result is discovered in Figure 2. Example 2 discusses the situation where one Retailer's price is higher than the upper bound of Feasible-Price interval and another Retailer's price is within Feasible-Price interval.

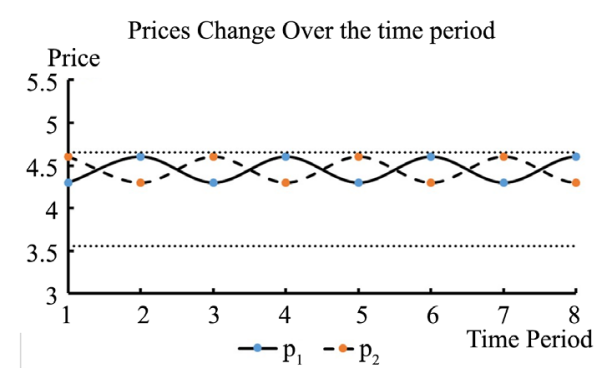

Figure 1. Example 1.

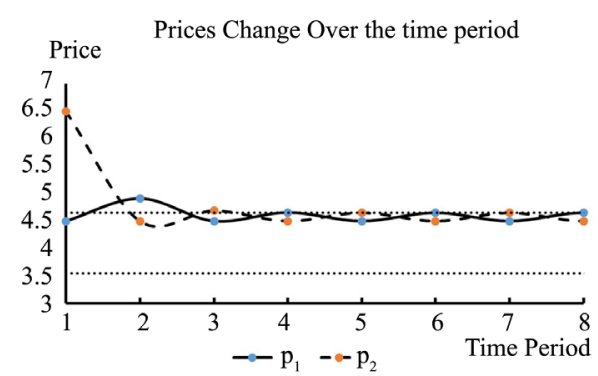

Figure 2. Example 2. 
First, we can see that Retailer 2's price is higher than Retailer 1's price in period 1; Retailer 1's price is higher than Retailer 2's in Period 2; Retailer 2's price is higher than Retailer 1's in period 3; and so on. This result is different from Example 1 because Retailers $1 \& 2$ are not exactly switching their prices in the first five periods. They just switch relative high/low price status.

Our results also show that Retailer 2's price is $44 \%$ higher than Retailer 1's price in period 1 and the price of Retailer lincreases to 4.91 above Feasible-Price interval in period 2. In other words, when a Retailer enters the monopoly market with a significantly high price, it may push other competing prices higher than its "reasonable price". Though Retailer 1's prices are pushed above Feasible-Price interval in Period 2, Retailer 2's price drops to Feasible-Price interval. This pattern continues through periods 1 to 5 . In addition, the range of the two Retailers' prices decreases as one Retailer's price is out of the Feasible-Price interval. In period 6 and beyond, both Retailer's prices are in the Feasible-Price interval. Specially, one price matches the upper bound of the Feasible-Price interval and the other price is slightly lower than the upper bound of the Feasible-Price interval.

Example 3. Initial prices for Retailers 1 and 2 are as follows: $p_{1}=4.5$ and $p_{2}=2$.

The result is discovered in Figure 3. Example 3 discusses the situation when the initial price of one retailer is lower than the lower bound of the Feasible-Price interval and another retailer's price in the Feasible-Price interval. Our results show that two retailers keep on switching at relatively high/low price status.

When Retailer 1 realizes that Retailer 2 provides a lower price in period 1, Retailer 1 would reduce its price in period 2. Since the initial price of Retailer 1 is close to the upper bound of Feasible-Price interval in period 1, the best solution to Retailer 1 is to keep its price at the lower bound of Feasible-Price interval in Period 2. At the same time, Retailer 2's price is pushed into Feasible-Price interval and both Retailers' prices are in the Feasible-Price interval in Period 2. The pattern of the two Retailers' prices continues similar to the pattern shown in Example 1. Combining Example 2 and Example 3, when one retailer's price falls inside the Feasible-Price interval and another Retailer's price is outside the Feasible-Price interval, the following observations hold:

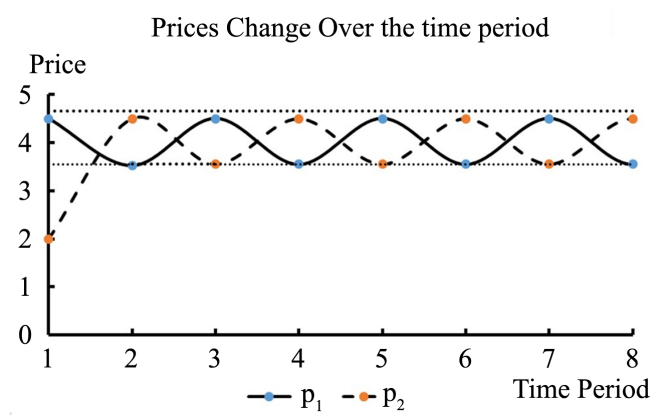

Figure 3. Example 3. 
1) The range of Retailer's prices will decrease over time until both prices are in the Feasible-Price interval.

2) In any period, at least one Retailer's price is in the Feasible-Price interval. Whether another Retailer's price falls in the Feasible-Price interval or not depends on the Retailers' prices in the previous period.

3) A Retailer with an initial price higher than upper bound of the Feasible-Price interval may increase its price to the upper bound of the Feasible-Price interval. A Retailer with an initial price lower than the lower bound of Feasible-Price interval may pull its final price to the lower bound of Feasible-Price interval.

Example 4. Initial prices for Retailers 1 and 2 are as follows: $p_{1}=6$ and $p_{2}=1$.

The result is discovered in Figure 4. Now we consider if both retailers' prices are out of the Feasible-Price Region. Based on prior analysis, when the initial price in period 1 is higher than the upper bound, market dynamics may force that price towards the upper bound. Conversely, when the initial price in period 1 is lower than the lower bound, market dynamics may push the final price to the lower bound. Example 4 has one price higher than the upper bound and the other price is lower than lower bound; the result is consistent with the previous observation and the final two prices are the upper bound and the lower bound.

In the previous three Examples, one retailer's initial price is inside of Feasible-Price interval. Hence, at least one retailer's price is insider of the Feasible-Price interval in every period in previous Examples.

However, when both retailers' prices are outside of Feasible-Price interval, it may take time for prices to migrate into Feasible-Price interval.

Example 5. Initial prices for Retailers 1 and 2 are as follows: $p_{1}=6$ and $p_{2}=5$.

The result is discovered in Figure 5. In Example 5, both Retailers' prices are higher than the upper bound. First, both Retailers' price will decrease to the upper bound.

We note also that the two Retailers keep on switching their relative prices at relative high/low positions. We infer that Retailer 1 initial price in period 1 is very high and risking a significant reduction in market share to Retailer 2, Retailer 1 will dramatically drop its price to a relatively lower price in period 2 .

Retailer 2's initial price is moderately higher than upper bound as well but there is no rush to reduce its price given the price of Retailer 1. Thus, the price reduction follows a gradual process in period 2 . Therefore, the relative high/low pattern still holds.

Example 6. Initial prices for Retailers 1 and 2 are as follows: $p_{1}=3$ and $p_{2}=2$.

The result is discovered in Figure 6. In Example 6, both Retailers' prices are below the lower bound. First, both Retailers' price will increase to the lower bound. In this case, Retailer 2 sets a very lower price in Period 1 but quickly 


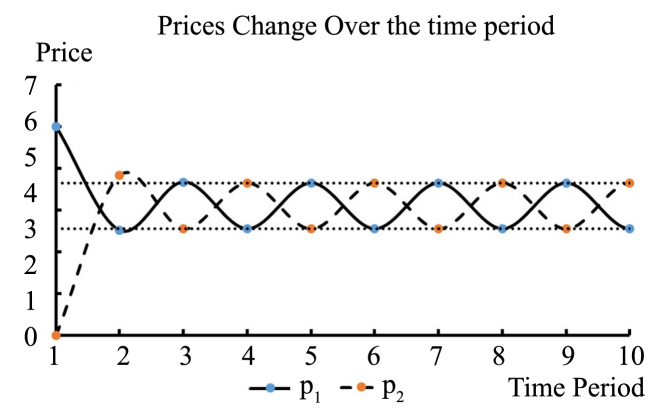

Figure 4. Example 4.

Prices Change Over the time period

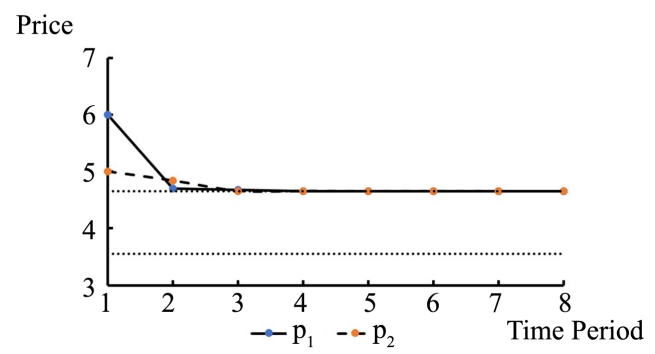

Figure 5. Example 5.

Prices Change Over the time period

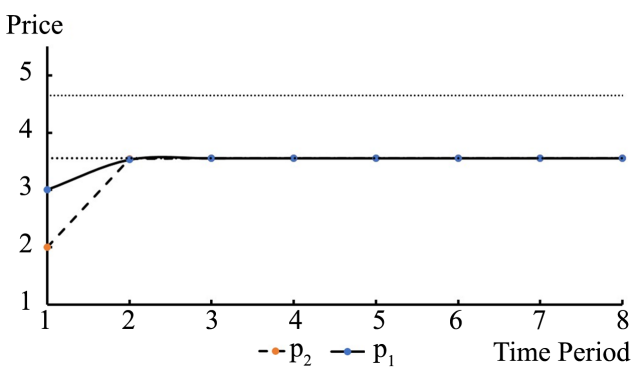

Figure 6. Example 6.

increases its price in Period 2 upon realizing that a higher unit profit can be obtained given the price of Retailer 1.

In a similar manner, Retailer 1 also sets its initial price below the lower bound though not as low as Retailer 2. Responding to the significant increase in price by Retailer 2, the price of Retailer 1 will increase though at slower rate in period 2. Again, the relative high/low price pattern still holds.

\subsection{Three Symmetric Retailers}

The base parameters for three symmetric Retailers are as follows: $a_{i}=30$, $b_{i}=2.5, \quad \beta_{i, j}=0.7, \omega_{i}=4, \gamma_{i}=20 \%, \forall i, j=1,2,3, i \neq j$.

From above parameters, we will have Feasible-Price interval $\left[\lambda^{\underline{N E}}(n), \lambda^{\overline{N E}}(n)\right]=[3.56,4.65]$.

Example 7. Initial prices for Retailers 1, 2, 3 are as follows: $p_{1}=4, p_{2}=4.5$ and $p_{3}=4.3$. 
The result is discovered in Figure 7. We show that Retailers' prices will converge to 4. In Example 1 involving two retailers, we reported that Retailers' prices depict a switching pattern. However, with three Retailers, the three prices will converge to one price.

The retailer with the highest price in period 1 will reduce its price to the point that it now charges the lowest price in period 2. Conversely, the Retailer with the lowest price in period 1 will increase its price momentarily in the next period. Eventually, the final equilibrium and stable price is equal to the initial lowest price.

Example 8. Initial prices for Retailers 1, 2, 3 are as follows: $p_{1}=4, p_{2}=4.5$ and $p_{3}=5$.

The result is discovered in Figure 8. In this scenario, Retailer 3 pricing in period 1 is above the Feasible Price interval when compared to the illustration in Example 7. Over time, all Retailers' prices will converge to about 4.

Example 9. Initial prices for Retailers 1, 2, 3 are as follows: $p_{1}=4, p_{2}=5$ and $p_{3}=6$.

The result is discovered in Figure 9. In Example 9, both Retailer 3 and Retailer 2 pricing in period 1 are higher than the upper bound of Feasible-Price interval. Once again, over time all Retailers' prices will converge to 4 .

Example 10. Initial prices for Retailers 1, 2, 3 are as follows: $p_{1}=5$, $p_{2}=5.5$ and $p_{3}=6$.

The result is discovered in Figure 10. When all retail prices are above the upper bound of the Feasible Price interval, all Retailers' prices will converge to the

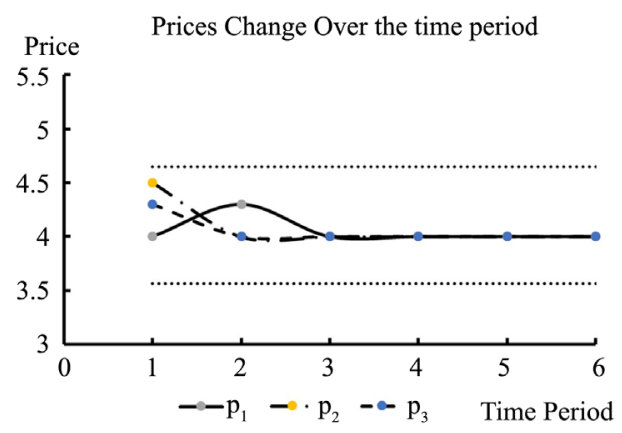

Figure 7. Example 7.

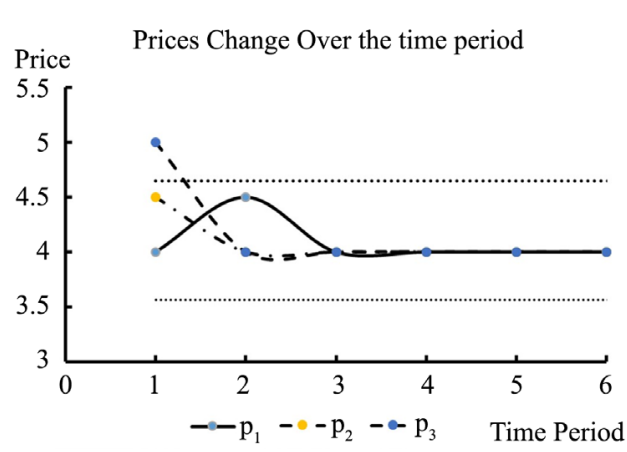

Figure 8. Example 8. 


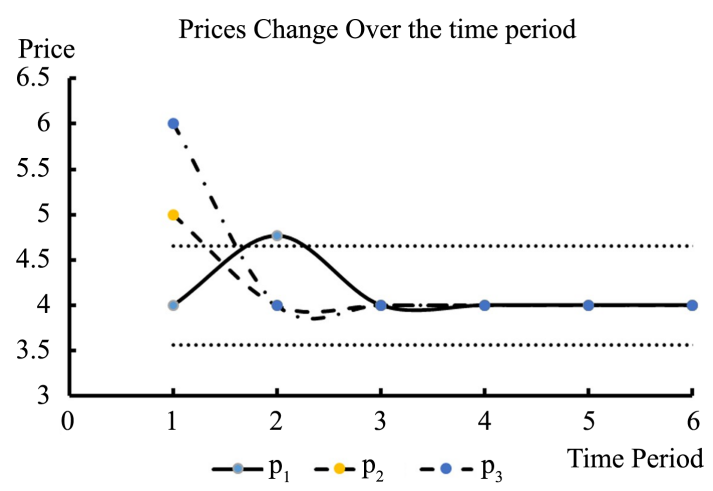

Figure 9. Example 9.

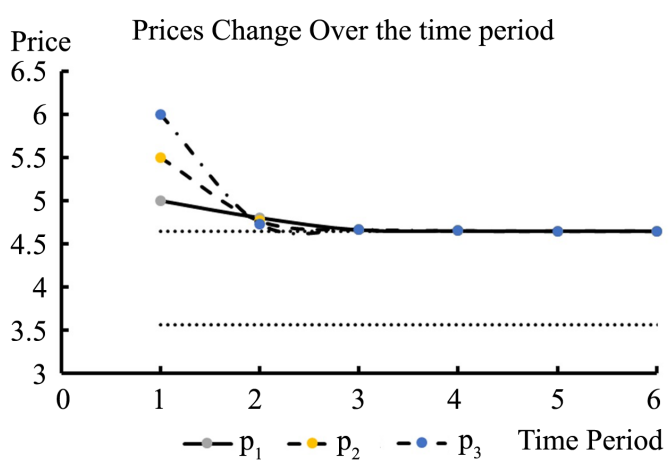

Figure 10. Example 10.

upper bound of the Feasible Price interval which is about 4.65. Comparing Example 7, 8 and 9, we observe that the final stable price is not to be affected by increasing and/or reducing one retailer's price.

Example 11. Initial prices for Retailers 1, 2, 3 are as follows: $p_{1}=4$, $p_{2}=4.5$ and $p_{3}=3.2$.

The result is discovered in Figure 11. Next we consider the reverse of Example 8 and Retailer 3's price in period 1 is the lowest at about 3.2 when compared to the prices of Retailer 1 and 2. The final stable price for all Retailers decreases to 3.60 from 4 because of the lowest threshold price of Retailer 3 .

Example 12. Initial prices for Retailers 1, 2, 3 are as follows: $p_{1}=4$, $p_{2}=2.5$ and $p_{3}=3.2$.

The result is discovered in Figure 12. The prices of Retailer 2 and 3 in period 1 are 2.5 and 3.2 respectively; both prices are below the lower bound of the Feasible Price interval. Ultimately, all Retailers' prices will converge at about 3.58 .

Example 13. Initial prices for Retailers 1,2, 3 are as follows: $p_{1}=2$, $p_{2}=2.5$ and $p_{3}=3.2$.

The result is discovered in Figure 13. In this last scenario, the prices of Retailer 1, 2 and 3 in period 1 are 2, 2.5 and 3.2. In the long term, all Retailers' prices below the lower bound of the Feasible price interval will converge at about 3.56 . 


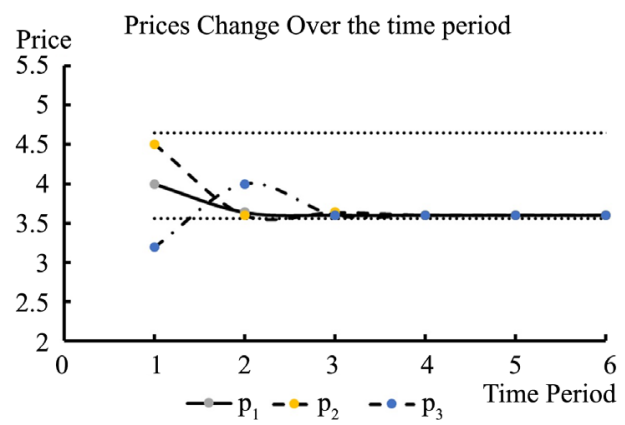

Figure 11. Example 11.

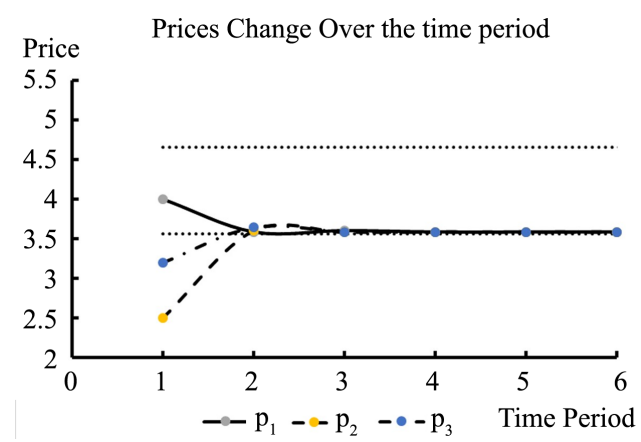

Figure 12. Example 12.

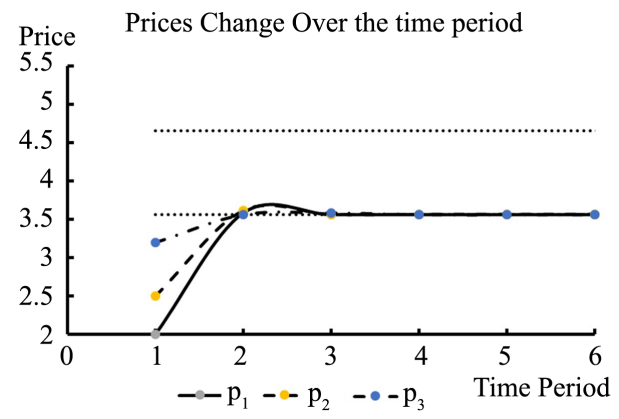

Figure 13. Example 13.

\subsection{Summary of Numerical Studies}

In the following table, we compare case with two retailers and the case with three or more retailers.

\begin{tabular}{cll}
\hline & \multicolumn{1}{c}{ Two retailers } & \multicolumn{1}{c}{ Three retailer or more } \\
\hline convergence & $\begin{array}{c}\text { May not converge, i.e. switch at two } \\
\text { fixed prices in Feasible-Price interval } \\
\text { may converge to one stable price. }\end{array}$ & Converge to one stable price \\
$\begin{array}{c}\text { Sensitivity to } \\
\text { the increment } \\
\text { of the price }\end{array}$ & $\begin{array}{l}\text { The final price tends to increase if one } \\
\text { retailer increases its initial price. }\end{array}$ & $\begin{array}{l}\text { The final price may not change if the } \\
\text { lowest initial price is not changed }\end{array}$ \\
$\begin{array}{c}\text { Sensitivity to } \\
\text { the decrement } \\
\text { of the price }\end{array}$ & $\begin{array}{l}\text { The final price tends to decrease if } \\
\text { one retailer decreases its initial price. }\end{array}$ & $\begin{array}{l}\text { The final price tends to decreases. } \\
\text { When more retailers are involved, the } \\
\text { tendency is more significant. }\end{array}$ \\
\hline
\end{tabular}




\section{Continued}

\begin{tabular}{cl}
\hline The retailer with the highest price in the current stage will provide the \\
Reaction & lowest price in the next period; \\
of Retailers & The retailer with the lowest price in the current stage will provide the \\
highest price in the next period.
\end{tabular}

Current research papers focus on empirical studies. Our paper provides a theoretical explanation of how retailers change prices under competition. The paper provides managerial insights to retailers. If the retailer faces one competitor nearby, he needs not low down his price rapidly because he and his competitor eventually will shuffle prices between the lower price and the high price. If the retailer faces two competitors, he needs to realize the price will go down to the lowest price. He can take advantage of the period between the current price and the lowest price. If the retailer faces three or more competitors, dropping the current price to the lowest price quickly may attract more customers.

\section{Conclusions}

The paper discusses the optimal pricing strategy under the price match policy. First, we analyzed the best response for each retailer facing different competitors (Lemma 1). We posit that the lowest price of other retailers increases the sensitivity of customers to the price and the tightness of the competition.

Further, the paper addresses the optimal strategy in different scenarios. When only two retailers are involved, the change of two retailers' prices over the time period is discovered in detail (Theorems $2 \& 3$ ). When more tailers are involved, the changes and the convergence have been explored in Theorems $4 \& 5$.

To illuminate theoretical results, the paper presents examples in symmetric cases. our results show that competition dramatically increases as the number of retailers increases.

We also find some counter-intuition results. Retailers generally believe that the lowest market price has more impact on prices in the final stationary status than the highest price in the market. The paper discovers that this finding is not only related to the relative values of the prices but it is also related to the position of prices. When all prices are higher than the lower bound of the feasible price region, the final status will be close to the lowest price (Examples 2, 5).

However, when the lowest price is less than the lower bound of the feasible price region, the final status will not be affected too much by it (Examples 3,6). The phenomena are counter-intuition and give important managerial insights to retailers. If a retailer provides an unreasonable lower price, the retailer can keep its price at the reasonable region which would bring him more profit.

The paper discusses that the outside price affects the competition between retailers. The future study can add an outside price as another random element.

\section{Conflicts of Interest}

The authors declare no conflicts of interest regarding the publication of this paper. 


\section{References}

[1] Writtenhouse, S. (2019) The 5 Best Price Comparison Apps: How to Find Deals and Save Money.

https://www.makeuseof.com/tag/6-price-comparison-apps-compared-best/

[2] Steele, C. (2019) The Best Shopping Apps to Compare Prices. https://www.pcmag.com/news/the-best-shopping-apps-to-compare-prices

[3] Ferreira, N.M. (2019) 25+ Best Price Comparison Websites and Apps You Need to Try. https://www.oberlo.com/blog/25-best-price-comparison-websites

[4] Chen, L., Nan, G.F. and Li, M.Q. (2018) Wholesale Pricing or Agency Pricing on Online Retail Platforms: The Effects of Customer Loyalty. International Journal of Electronic Commerce, 22, 576-608. https://doi.org/10.1080/10864415.2018.1485086

[5] Wang, R., Nan, G., Chen, L. and Li, M. (2020) Channel Integration Choices and Pricing Strategies for Competing Dual-Channel Retailers. IEEE Transactions on Engineering Management, Early Access, 1-15. https://doi.org/10.1109/TEM.2020.3007347

[6] Loria, C. (2019) How Consumers Compare Prices to Make Purchase Decisions. https://blog.wiser.com/how-consumers-compare-prices-to-make-purchase-decisions/

[7] eMarketer (2013) Dynamic Pricing Helps Keep Pace with Savvy Consumers. https://www.emarketer.com/Article/Dynamic-Pricing-Helps-Keep-Pace-with-Savvy -Consumers/1009897

[8] Png, I.P.L. and Hirshleifer, D. (1987) Price Discrimination through Offers to Match Price. Journal of Business, 60, 365-383. https://doi.org/10.1086/296402

[9] Salop, S. (1986) Practices That (Credibly) Facilitate Oligopoly Coordination. In: Stiglitz, J. and Mathewson, F., Eds., New Developments in the Analysis of Market Structure, MIT Press, Cambridge, MA, 265-290. https://doi.org/10.1007/978-1-349-18058-5_9

[10] Doyle, C. (1988) Different Selling Strategies in Bertrand Oligopoly. Economic Letters, 28, 387-390. https://doi.org/10.1016/0165-1765(88)90018-3

[11] Logan, J.W. and Lutter, R.W. (1989) Guaranteed Lowest Prices: Do They Facilitate Collusion. Economic Letters, 31, 189-192. https://doi.org/10.1016/0165-1765(89)90197-3

[12] Chen, Y., Narasimhan, C. and Zhang, Z. (2001) Consumer Heterogeneity and Competitive Price-Matching Guarantees. Marketing Science, 20, 300-314. https://doi.org/10.1287/mksc.20.3.300.9766

[13] Hviid, M. and Shaffer, G. (1999) Hassle Costs: The Achilles' Heel of Price-Matching Guarantees. Journal of Economic Management and Strategy, 8, 489-521.

[14] Kireyev, P., Kumar, V. and Ofek, E. (2017) Match Your Own Price? Self-Matching as a Retailer's Multichannel Pricing Strategy. Marketing Science, 36, No. 6. https://doi.org/10.1287/mksc.2017.1035

[15] Zhang, Z.J. (1995) Price-Matching Policy and the Principle of Minimum Differentiation. Journal of Industrial Economics, 43, 287-299. https://doi.org/10.2307/2950581

[16] Gallego, G. and Hu, M. (2014) Dynamic Pricing of Perishable Assets under Competition. Management Science, 60, No. 5. https://doi.org/10.1287/mnsc.2013.1821

[17] Cabral, L. (2011) Dynamic Price Competition with Network Effects. The Review of Economic Studies, 78, 83-111. https://doi.org/10.1093/restud/rdq007

[18] Hoernig, S. (2012) Strategic Delegation under Price Competition and Network Ef- 
fects. Economics Letters, 117, 487-489. https://doi.org/10.1016/j.econlet.2012.06.045

[19] Adida, E. and Perakis, G. (2010) Dynamic Pricing and Inventory Control: Uncertainty and Competition. Operations Research, 58, 289-302.

https://doi.org/10.1287/opre.1090.0718

[20] Martínez-de-Albéniz, V. and Talluri, K., (2014) Dynamic Price Competition with Fixed Capacities. Management Science, 57, No. 6. https://doi.org/10.1287/mnsc.1110.1337

[21] Dreyer, B. and Grønhaug, K. (2004) Uncertainty, Flexibility, and Sustained Competitive Advantage. Journal of Business Research, 57, 484-494. https://doi.org/10.1016/S0148-2963(02)00315-6

[22] Finn, M.G. (2000) Perfect Competition and the Effects of Energy Price Increases on Economic Activity. Journal of Money, 32, 400-416. https://doi.org/10.2307/2601172

[23] Hastings, J.S. (2004) Vertical Relationships and Competition in Retail Gasoline Markets: Empirical Evidence from Contract Changes in Southern California. American Economic Review, 94, 317-328.

https://doi.org/10.1257/000282804322970823

[24] Bernstein, F. and Federgruen, A. (2003) Pricing and Replenishment Strategies in a Distribution System with Competing Retailers. Operations Research, 51, 409-426. https://doi.org/10.1287/opre.51.3.409.14957

[25] Bernstein, F. and Federgruen, A. (2004) Dynamic Inventory and Pricing Models for Competing Retailers. Naval Research Logistics, 51, 258-274.

https://doi.org/10.1002/nav.10113

[26] Bernstein, F., Chen, F. and Federgruen, A. (2006) Coordinating Supply Chains with Simple Pricing Schemes: The Role of Vendor Managed Inventories. Management Science, 52, 1483-1492. https://doi.org/10.1287/mnsc.1060.0564

[27] Bernstein, F. and Federgruen, A. (2004) Comparative Statics, Strategic Complements and Substitutes in Oligopolies. Journal of Mathematical Economics, 40, 713-746. https://doi.org/10.1016/S0304-4068(03)00086-7

\section{Appendix: Proofs}

All appendix can be found at

https://drive.google.com/file/d/1_VgFZoZHrrbnUa3Lx3h7PTInM_UaaWHM /view? usp=sharing 